\title{
KONTRA-FUNDAMENTALISME AGAMA MELALUI PENGUATAN KARAKTER KEBANGSAAN BAGI PARA PELAJAR DI KOTA BANDAR LAMPUNG
}

\author{
Maulana Mukhlis*, Yulianto \\ Jurusan Ilmu Pemerintahan FISIP Universitas Lampung, Bandar Lampung \\ Jl. Prof. Sumantri Brojonegoro No.1 Bandar Lampung 35145 \\ Penulis Korespodensi : maulanamukhlis1978@gmail.com
}

\begin{abstract}
Abstrak
Salah satu tantangan dalam menjaga keutuhan Negara Kesatuan Republik Indonesia adalah semakin menurunnya kesadaran kebangsaan dan semakin menguatnya komodifikasi agama yang bukan hanya dalam konteks urusan ibadah namun juga merambah pada urusan politik kenegaraan. Implikasi dari kedua isu tersebut adalah semakin tergerusnya ideologi Pancasila pada diri warga negara salah satunya pada kalangan pelajar. Tujuan akhir dari pengabdian ini adalah terbentuknya komunitas "Pelajar Kontra Fundamentalisme" di Kota Bandar Lampung yang tumbuh dari pengetahuan dan kesadaran para pelajar SMA yang diperoleh melalui pendampingan yang tepat dan berkelanjutan. Metode yang dipakai dalam pencapaian tujuan PKM adalah sosialisasi, pendampingan, serta pembinaan sehingga para pelajar memiliki pengetahuan komprehensif tentang kontra fundamentalisme agama dan wawasan kebangsaan sehingga mampu bersikap moderat dalam kehidupan berbangsa dan bermasyarakat.Obyek dari PKM ini adalah para pelajar SMA di Kota Bandar Lampung sebagai entitas kelompok masyarakat produktif yang berpotensi menjadi penangkal bagi munculnya gerakan fundamentalisme, radikalisme, kekerasan atas nama agama. Hasil pengabdian kepada masyarakat yang dilakukan secara kuantitatif terbukti telah meningkatkan aspek pemahaman (knowledge) para pelajar sebesar 62,8\% dan 98\% pada aspek komitmen untuk berperilaku moderat dan bersikap untuk mempertahankan idiologi Pancasila dan keutuhan Negara Kesatuan Republik Indonesia.
\end{abstract}

Kata Kunci: Kontra-Fundamentalisme, Pelajar, Wawasan Kebangsaan,

\section{Pendahuluan:}

Saat ini, fenomena fundamentalisme agama mendominasi dalam beberapa praktik keagamaan yang sering memicu berbagai pertentangan, konflik, dan pertikaian yang terjadi di Indonesia. Hal tersebut semakin memperlihatkan bahwa wacana pluralisme dan kebebasan agama masih menjadi salah satu problem bagi kehidupan sosial keagamaan di Indonesia di tengah upaya pemerintah dalam membangun tatanan masyarakat yang lebih harmonis (Zuliyanto, 2018).

Menguatnya paham fundamentalisme agama di Indonesia dibuktikan dengan survei yang dilakukan oleh Alvara Research Center yang dilakukan pada Oktober 2017 tentang menguatnya gerakan fundamentalis di Indonesia. Fakta yang cukup riskan dari survei tersebut adalah bahwa paham fundamentalisme telah masuk pada dunia pendidikan serta aparat sipil negara (ASN). Angka
19,4\% merupakan jumlah yang besar untuk jumlah ASN yang tidak setuju Pancasila sebagai ideologi negara. $18,1 \%$ pegawai swasta menyatakan tidak setuju dengan ideologi Pancasila, dan 9,1\% pegawai BUMN tidak setuju dengan ideologi Pancasila (Rikang, 2019).

Isu menguatnya fundamentalisme agama di dunia pendidikan terus mengemuka. Survei yang dilakukan Alvara Research Center dan Mata Air Foundation pada Oktober 2017 dengan melibatkan 1.800 Mahasiswa di Indonesia di 25 universitas unggulan se-Indonesia dan 2.400 pelajar SMAN unggulan di Pulau Jawa serta kota-kota besar di Indonesia. Hasil Survei tersebut sebagaimana dalam Gambar 1 menunjukkan bahwa 23,5\% mahasiswa dan $16,3 \%$ pelajar mendukung gerakan ISIS. Bahkan, sebanyak $23,3 \%$ pelajar dan $23,4 \%$ mahasiswa siap berjihad untuk mendirikan negara khilafah. 
Survei mengenai menguatnya fundamentalisme agama dikalangan pelajar dan mahasiswa juga dilakukan Pusat Pengkajian Universitas Islam Negeri Syarif HidayatullahConvey Indonesia, Jakarta. Survei yang dilakukan pada September-Oktober 2017 yang melibatkan 1.522 siswa dan 337 mahasiswa sebagai responden di 34 provinsi di Indonesia. Hasil survei menunjukan hasil sebagai berikut: 58,5\% menyatakan sikap radikal, 20,1\% menyatakan moderat, dan lain-lain 21,4\%.

Menguatnya paham fundamentalisme agama yang ditinjau berdasarkan survei dan penelitian berskala nasional, fundamentalisme agama juga menguat pada survei di beberapa daerah dengan didukung dengan kasus-kasus fundamentalisme agama yang muncul, tidak terkecuali di Provinsi Lampung. Menurut Badan Nasional Penanggulangan Terorisme (BNPT), pada November 2017, Lampung termasuk ke dalam lima provinsi dengan fundamentalisme agama tertinggi, lima provinsi tersebut adalah Bengkulu (58,58\%), Gorontalo $(58,48 \%)$, Sulawesi Selatan $(58,42 \%)$, Lampung $(58,38 \%)$, dan Kalimantan Utara (58,30\%) (Pardiana, 2018).

Forum Koordinasi Pencegahan Terorisme (FKPT) Lampung pada tahun 2016 menyatakan bahwa terdapat enam kabupaten/kota di Provinsi Lampung yang memiliki tingkat kerawanan terpapar paham fundamentalisme agama tertinggi. Enam daerah tersebut yakni, Bandar Lampung, Pringsewu, Lampung Tengah, Lampung Utara, Lampung Selatan, dan Lampung Timur. Forum Koordinasi Pencegahan Terorisme (FKPT) juga mengungkapkan bahwa komposisi kelompok di Lampung yang terpapar paham terpapar paham fundamentalisme agama tertinggi adalah, 63.6\% lulusan SMA, 16.4\% lulusan perguruan tinggi, 5.5\% merupakan drop out dari perguruan tinggi (Yasland, 2016).

Kekuatan fundamentalisme agama memang masih sangat kecil jika dibandingkan dengan seluruh jumlah masyarakat Indonesia, tetapi hal ini bukan pembenaran bagi negara dan seluruh elemen masyarakat untuk tidak mencegah menguatnya paham fundamentalisme agama. Bukan tanpa alasan, penyebaran dan pertumbuhan fundamentalisme agama sudah tersebar di daerahdaerah strategis di Indonesia. Fundamentalisme agama merupakan ancaman bagi kestabilan negara dari tindak kekerasan hingga pemikiran liar untuk merubah dasar ideologi bangsa Indonesia.

Berdasarkan cakupan dan ruang lingkupnya, perlawanan terhadap fundamentalisme agama tidak hanya menjadi tugas bagi pemerintah, namun menjadi tugas semua pihak dalam wilayah negara, masyarakat, dan juga dari sektor kelompok civil society. Penanganan fundamentalisme agama yang dilakukan negara seolah hanya terpaku pada urusan keamanan dan mengaburkan penanganan melalui peran aktif masyarakat, akibatnya permasalahan fundamentalisme seperti gerakan tanpa ujung. Pelibatan organisasi masyarakat dirasa begitu penting didasarkan pada pemikiran bahwa pemerintah mempunyai keterbatasan dalam ketersediaan sumber dana, sumber daya manusia dan tekhnologi, peran serta masyarakat (civil society) jalinan kerja sama antar masyarakat (Imansari, 2019).

Bagi para pelajar SMA, manfaat pertama setelah adanya kegiatan pengabdian kepada masyarakat (PKM) ini adalah terbentuknya pelajar kontra fundamentalisme yang memiliki pengetahuan sebagai dasar membangun sikap moderasi sosio-religius dalam memupuk karakter kebangsaan secara lebih maksimal. Hasil pengabdian ini juga semakin menegaskan pentingnya posisi dan peran pelajar SMA dalam mencegah, menangkal, dan menghadapi tantangan kekerasan mengatasnamakan agama di Indonesia.

Adapun secara praktis, manfaat kedua dari pengabdian ini adalah bahwa model kontraradikalisme yang ada Bandar Lampung ini dapat dipergunakan oleh pemerintah untuk mengembangan pendekatan atau strategi alternatif untuk lebih mengoptimalkan efektifitas kebijakan deradikalisasi terutama terkait dengan peran pelajar SMA di dalamnya. Dalam jangka panjang, peningkatan karakter kebangsaan ini akan menjadi modal berharga bagi terjaminnya masa depan Negara Kesatuan Republik Indonesia.

\section{Bahan dan Metode:}

Pengabdian kepada Masyarakat dalam bentuk "Pendampingan Kontra-Fundamentalisme melalui Penguatan Karakter Kebangsaan Pada Siswa SMA di Bandar Lampung" ini terdiri atas beberapa arahan pokok sebagai solusi atau upaya yang telah dilakukan dalam rangka menjawab permasalahan yang dihadapi atau situasi saat ini yang dialami mitra, yakni para pelajar di Kota 
Bandar Lampung. Solusi-solusi tersebut diuraikan dalam tabel berikut.

Tabel 1. Solusi atas Permasalahan Mitra

\begin{tabular}{|c|c|}
\hline Permasalahan Mitra & Solusi \\
\hline $\begin{array}{l}\text { Pemahaman para } \\
\text { pelajar SMA tentang } \\
\text { konsep kontra- } \\
\text { fundamentalisme, } \\
\text { moderasi sosio- } \\
\text { religius, serta wawasan } \\
\text { kebangsaan masih } \\
\text { minim }\end{array}$ & $\begin{array}{l}\text { Perlu meningkatkan } \\
\text { pemahaman para } \\
\text { pelajar tentang konsep } \\
\text { kontra- } \\
\text { fundamentalisme, } \\
\text { moderasi sosio- } \\
\text { religius, serta wawasan } \\
\text { kebangsaan }\end{array}$ \\
\hline $\begin{array}{l}\text { Entitas pelajar SMA } \\
\text { selama ini dianggap } \\
\text { oleh kalangan } \\
\text { masyarakat umum } \\
\text { sebagai lembaga } \\
\text { pendidikan yang } \\
\text { belum dioptimalkan } \\
\text { fungsinya dalam upaya } \\
\text { menanggulangi } \\
\text { kekerasan atas nama } \\
\text { agama }\end{array}$ & $\begin{array}{l}\text { Perlu membangun } \\
\text { kesadaran bahwa } \\
\text { Pelajar SMA memiliki } \\
\text { potensi dan } \\
\text { karakteristik untuk } \\
\text { terlibat dalam } \\
\text { kebijakan pemerintah } \\
\text { sehingga anggapan } \\
\text { publik tersebut tidak } \\
\text { semakin membesar }\end{array}$ \\
\hline $\begin{array}{l}\text { Para pelajar SMA } \\
\text { secara umum sangat } \\
\text { jarang mengikuti } \\
\text { pembekalan atau } \\
\text { pembinaan terkait } \\
\text { dengan wawasan } \\
\text { kebangsaan }\end{array}$ & $\begin{array}{l}\text { Perlu uji coba dan } \\
\text { pendampingan kepada } \\
\text { para pelajar SMA }\end{array}$ \\
\hline $\begin{array}{l}\text { Belum terbentuk } \\
\text { komunitas "Pelajar } \\
\text { Kontra- } \\
\text { Fundamentalisme" di } \\
\text { Bandar Lampung }\end{array}$ & $\begin{array}{l}\text { Perlu menginisisasi } \\
\text { dan mendampingi } \\
\text { pembentukan } \\
\text { Komunitas "Pelajar } \\
\text { Kontra } \\
\text { Fundamentalisme" di } \\
\text { Bandar Lampung }\end{array}$ \\
\hline $\begin{array}{l}\text { Kerja sama dengan } \\
\text { FKPT Provinsi } \\
\text { Lampung belum } \\
\text { terbangun maksimal }\end{array}$ & $\begin{array}{l}\text { Perlu desain } \\
\text { kolaborasi dengan } \\
\text { pihak lain di luar } \\
\text { sekolah }\end{array}$ \\
\hline
\end{tabular}

Para pihak yang terlibat dalam kegiatan pengabdian ini adalah:

1. Ketua Forum Komunikasi Penanggulangan Terorisms (FKPT) Provinsi Lampung.

2. Merupakan forum yang dibentuk oleh BNPT sebagai kepanjangan tangan di daerah-daerah.
Keterlibatan FKPT penting untuk merubah paradigma pemikiran pelajar bahwa mereka memiliki kebebasan mutlak dalam berekspresi. Padahal, kebebasan berekspresi tetap harus dilakukan dalam bingkai menjaga keutuhan Negara Kesatuan Republik Indonesia.

3. Ketua Dewan Pengurus Yayasan Pembina Universitas Lampung.

4. Merupakan salah satu yayasan di bawah naungan Universitas Lampung yang memiliki fungsi pelayanan sosial dan pendidikan melalui penyelenggaraan SMA YP Unila Bandar Lampung. Saat ini, SMA ini memiliki siswa sebanyak 1.147 siswa sehingga masuk kategori sekolah tingkat menengah terbesar di Provinsi Lampung. Oleh karena itu, pilihan kepada SMA YP Unila sebagai lokasi pengabdian kepada masyarakat sangat argumentatif karena memiliki kelompok sasaran yang sangat banyak.

5. Dewan Guru SMA Yayasan Pembina Universitas Lampung.

6. Salah satu aktor yang mempengaruhi penyelenggaraan dan kualitas sebuah program di sekolah adalah adanya peran guru. Guru menjadi contoh sangat baik bagi siswa dalam berperilaku. Oleh karena itu, salah satu tahapan dari pengabdian kepada masyarakat ini adalah dengan melibatkan para guru sehingga upaya keberlanjutan dari program atau hasil dari kegiatan pengabdian kepada masyarakat dapat terjaga dan berkesinambungan.

\section{Hasil dan Pembahasan:}

Deskripsi Kegiatan: Pengabdian dengan judul Pendampingan Kontra-Fundamentalisme Melalui Penguatan Karakter Kebangsaan Pada Siswa SMA di Bandar Lampung" ini terdiri atas beberapa metode pokok sebagai jawaban atau upaya yang perlu dilakukan dalam rangka menjawab permasalahan yang dihadapi atau situasi saat ini terkait kondisi mitra. Secara substansi deskripsi kegiatan yang akan didiseminasikan dalam pengabdian ini adalah sebagai berikut:

1. Penyuluhan tentang Kontra Fundamentalisme Agama.

2. Sosialisasi Wawasan Kebangsaan bagi Pelajar.

3. Pendampingan Kolaborasi kepada Para Guru.

4. Pendampingan Pembentukan Komunitas Pelajar Kontra Fundamentalisme. 
Analisis Hasil Kuantitatif: Dalam rangka mengevaluasi dan melihat kemanfaatan hasil pengabdian kepada masyarakat dalam hal peningkatan pemahaman, maka dilakukan pre-test dan post test terhadap seluruh peserta (pelajar). Pertanyaan pre-test yang dilakukan sebelum sosialisasi atau penyuluhsan dilaksanakan serta pertanyaan post-test yang dilakukan setelah sosialisasi atau penyuluhan adalah pertanyaan yang sama sehingga dapat diketahui tingkat perbandingan nilainya antara sebelum dan setelah sosialisasi atau penyuluhan tentang fundamentalisme, kontra fundamentalisme, dan peningkatan wawasan kebangsaan.

Hasil dan pembahasan dalam sub bab ini berisi hasil-hasil temuan kegiatan pengabdian dan pembahasannya secara ilmiah diawali dengan temuan hasil evaluasi awal (pre-test) dan perbandingannya dengan evaluasi akhir (post-test) terhadap data 47 kuisioner yang dianggap valid. Pada aspek pengetahuan, terdapat 7 (tujuh) pertanyaan awal untuk mengukur pemahaman pelajar terhadap konsep fundamentalisme, kontrafundamentalisme, ideologi, moderat, hijrah, bhinneka tunggal ika, dan konsep negara khilafah.

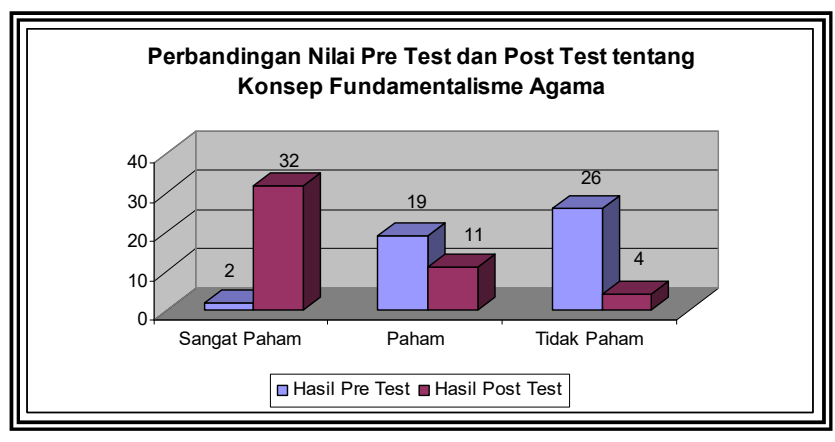

Bagan 1. Hasil Pre Test dan Post Test terkait Konsep Fundamentalisme Agama

Hasil pre-test pada bagan 1 menunjukkan bahwa dari 47 (empat puluh tujuh) pelajar, hanya 2 orang (4\%) yang sangat paham konsep fundamentalisme agama, hanya $40 \%$ yang paham konsep fundamentalisme agama. Sedangkan yang tidak paham sebanyak 26 pelajar atau 55\%. Jika dibandingkan dengan hasil pos-test menunjukkan terjadi kenaikan dari 2 pelajar menjadi 32 pelajar yang sangat paham. Penurunan paham dari 19 tinggal menjadi 11 dan penurunan tidak paham dari 26 peserta hanya menjadi 4 peserta saja yang masih belum paham tentang konsep fundamentalisme agama.

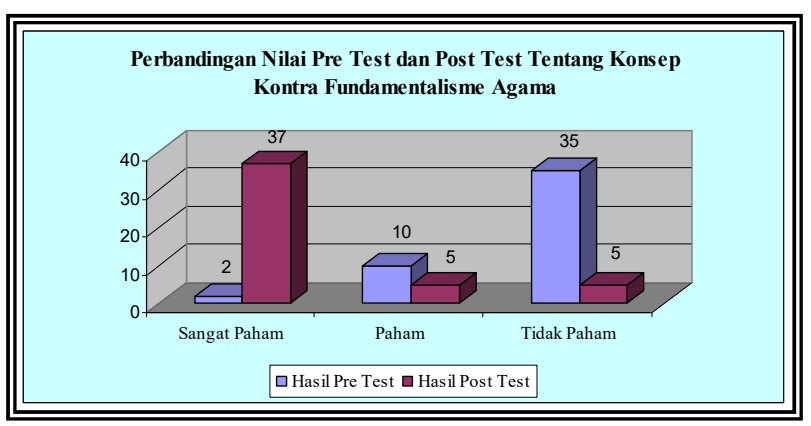

Bagan 2. Hasil Pre Test dan Post Test terkait Konsep Kontra-Fundamentalisme

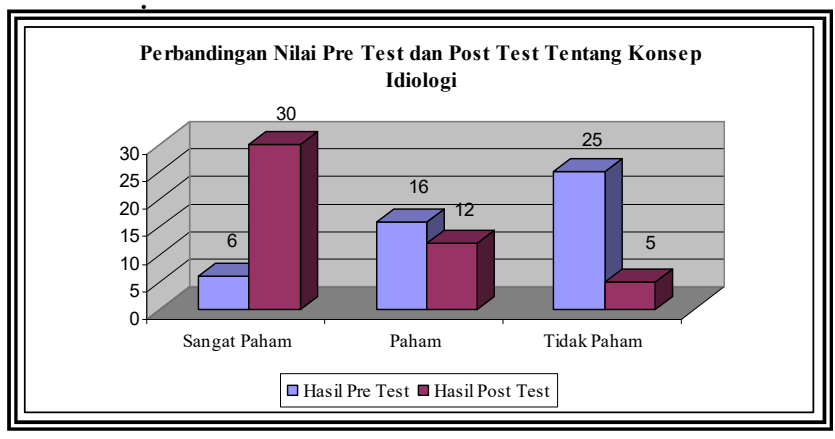

Bagan 3. Hasil Pre Test dan Post Test Terkait dengan Konsep Idiologi

Berikutnya berkaitan dengan pertanyaan moderat dan hijah dalam perspektif isu kekinian terkait komodifikasi agama yang sedang marak di kalangan artis. Hijrah yang berarti pindah, saat ini menjadi role model baru dalam masyarakat. Hijrah saat ini sering diartikan sebagai proses berpindah dari perilaku yang belum sesuai dengan syariat ke perilaku yang sesuai dengan syariat. Hal itu banyak dilakukan oleh para artis. Adapun moderat dimaknai sebagai sikap jalan tengah.

Pertanyaan berikutnya menyangkut sikap adalah tentang apakah para peserta mau jika seandainya diajak bergabung ke ISIS atau menolaknya, apakah peserta tetap bersepakat bahwa Pancasila merupakan idiologi ideal bagi bangsa Indonesia, serta apakah Negara Kesatuan Republik Indonesia tetap relevan untuk dipertahankan. Hal yang patut disyukuri adalah bahwa pada pada ketiga aspek sikap ini sebanyak $98 \%$ berada pada jawaban yang cukup baik. 


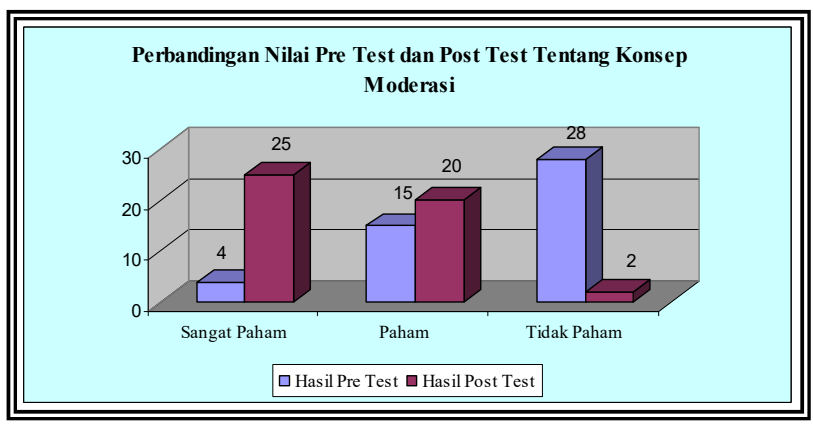

Bagan 4. Hasil Pre Test dan Post Test terkait dengan Konsep Moderasi

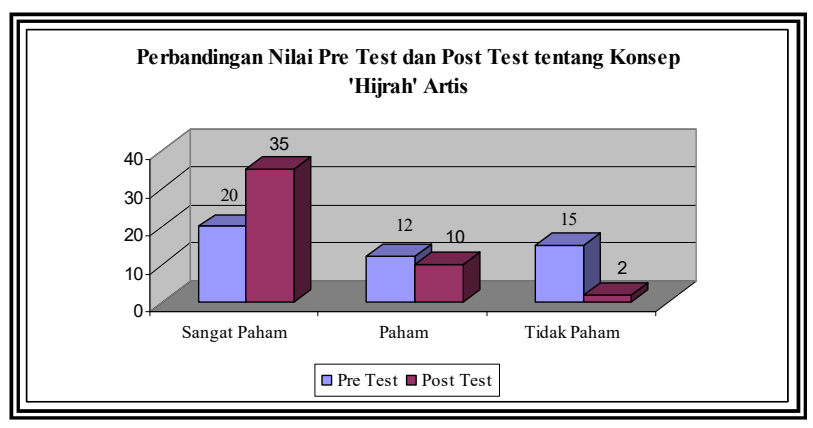

Bagan 5. Hasil Pre Test dan Post Test terkait dengan Konsep 'Hijrah' Artis

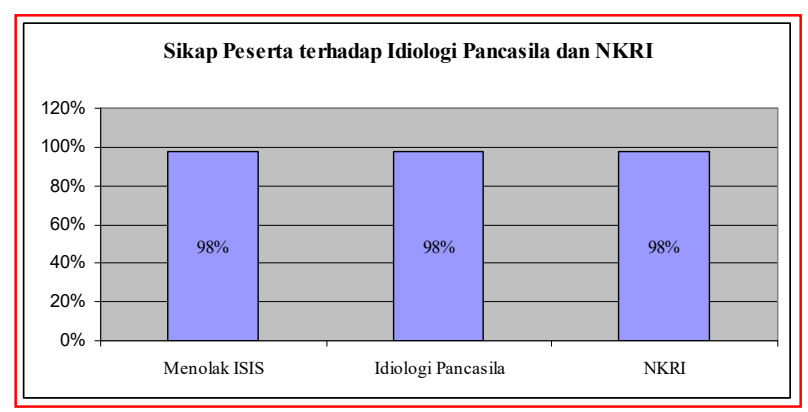

Bagan 6. Gambaran Sikap ke ISIS, Idiologi Pancasila, dan NKRI

Pertanyaan pada bagian terakhir dalam aspek perilaku adalah bagaimana para pelajar SMA YP Unila melakukan upaya kontrafundamentalisme. Jawaban pada aspek ini justru lebih kecil hasilnya yakni hanya sekitar $12 \%$ peserta yang memahami bagaimana caranya. Dalam konteks ini, maka kegiatan pengabdian kepada masyarakat harus mampu meningkatkan aspek perilaku ini.

Pasca kegiatan pengabdian pada tahap kedua, diberikan pertanyaan post-test sehingga dapat diketahui perbandingannya dengan hasil awal, baik pada aspek pengetahuan, sikap, maupun ketrampilan. Pada aspek prasyarat, peserta meyakini bahwa sekolah adalah sebuah lembaga pendidikan yang memiliki potensi cukup besar dalam membantu pemerintah dalam meneguhkan komitmen kebangsaan.

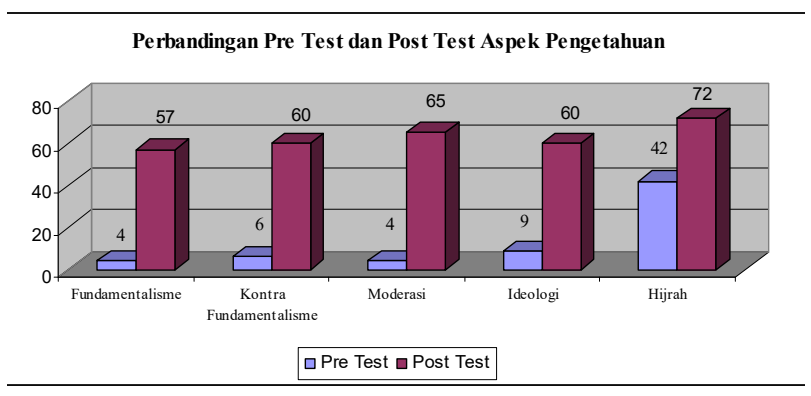

Bagan 7. Perbandingan Pre Test dan Post Test Pada Aspek Pengetahuan

Data pada Bagan 7 menunjukkan bahwa dengan pertanyaan yang sama, terjadi peningkatan pemahaman terkait konsep dasar tentang fundamentalisme, kontra fundamentalisme, moderasi, ideologi, dan hijrah. Secara rata-rata, terdapat peningkatan pada aspek pengetahuan sebesar $62,8 \%$.

Pada pertanyaan terkait dengan sikap, terjadi peningkatan kapasitas peserta dari $98 \%$ menjadi 100\% dan cenderung sangat yakin sehingga risiko turunnya aspek sikap tidak menjadi tantangan yang berarti dalam aspek ini. Adapun pada aspek perilaku, terjadi kenaikan yang sangat besar dari sebelumnya hanya $16 \%$ menjadi $98 \%$ artinya hampir seluruh peserta mengakui bahwa kekerasan yang mengatasnamakan agama dan upaya untuk mengganti idiologi Pancasila adalah musuh bersama yang harus dihadapi secara bersama dalam upaya menjaga keutuhan bangsa dan negara Indonesia

Analisis Hasil Kualitatif: Hasil pengabdian kepada masyarakat juga berhasil membangun kesadaran pada pelajar SMA di Bandar Lampung bahwa Negara Kesatuan Republik Indonesia (NKRI) yang terbangun dari berbagai macam agama, etnis, suku, budaya, dan bahasa yang kesemuanya memiliki kontribusi dalam sejarah perjuangan bangsa harus dipertahankan semaksimal mungkin. Kesadaran ini harus selalu dimunculkan agar para pelajar bisa memahami bahwa Indonesia ada untuk semua atau bukan hanya untuk satu golongan saja. Tujuan tersebut semakin argumentatif karena Indonesia kini dihadapkan pada 
satu kondisi yakni tantangan untuk mendamaikan apa yang disebut dengan ekstrem kanan (fundamental-inklusif) dan ekstrem kiri (liberalsekuler) dalam kehidupan beragama dan bahkan dalam kehidupan bernegara.

Oleh karena itu, perlu dibangun cara berpikir dan bernarasi sehingga komponen bangsa tidak terjebak dalam dua sekat ruang-ruang sosial yang merusak wawasan kebangsaan. Pada titik ini, sikap moderat sebagai integrasi ini ajaran agama apapun dengan keadaan masyarakat multikultural di Indonesia saat ini perlu disinergikan dengan kebijakan yang diambil oleh pemerintah serta didukung melalui manifestasinya dalam sistem pendidikan di sekolah. Kelompok pelajar sebagai bagian dari kelompok masyarakat yang produktif tentu memiliki kemampuan dan potensi untuk mendorong pemerintah agar upaya meneingkatkan wawasan kebangsaan dapat dapat terwujud serta kekerasan atas nama agama di Indonesia dapat dihilangkan sama sekali.

\section{Kesimpulan}

Obyek dari pengabdian kepada masyarakat ini adalah para pelajar SMA di Kota Bandar Lampung sebagai entitas kelompok masyarakat produktif yang berpotensi menjadi penangkal bagi munculnya gerakan fundamentalisme, radikalisme, dan kekerasan atas nama agama (Islam) khususnya di Provinsi Lampung. Hasil pengabdian kepada masyarakat yang telah dilakukan secara kuantitatif terbukti meningkatkan aspek pemahaman para pelajar sebesar $62,8 \%$ dan $98 \%$ pada aspek komitmen untuk berperilaku moderat dan bersikap untuk mempertahankan idiologi Pancasila dan keutuhan Negara Kesatuan Republik Indonesia. Adapun secara kualitatif adalah telah terbentuknya "Pelajar Kontra Fundamentalisme" yang tumbuh dari pengetahuan dan kesadaran para pelajar SMA atas bahaya kekerasan atas nama agama sehingga upaya kontra-fundamentalisme adalah tanggung jawab bersama seluruh komponen bangsa.

Kegiatan pengabdian kepada masyarakat ini telah memberikan pemahaman komprehensif kepada para pelajar tentang pengetahuan mengenai bentuk dan model fundamentalisme agama sehingga berpotensi masuk ke lingkungan sekolah. Pengetahuan dan kesadaran tersebut berikutnya berimplikasi positif bagi sikap para pelajar yang moderat baik secara sosial (sikap terhadap keragaman dan dinamika keragaman di Indonesia) serta moderasi religius (sikap dalam beragama agar tidak terlalu fanatik berlebihan sehingga menyalahkan agama lain) untuk menangkal ancaman kekerasan atas nama agama dengan optimasi potensi yang dimiliki oleh para pelajar dengan jumlah yang sangat besar.

Hasil jangka panjang dari kegiatan pengabdian kepada masyarakat ini adalah optimisme akan terwujudnya pelajar (sebagai pribadi) dan lingkungan sekolah formal (secara institusi) yang tanggap terhadap potensi dijadikannya sekolah sebagai wadah pembibitan kekerasan atas nama agama di Indonesia. Pelajar di Bandar Lampung berkomitmen penuh menjadi pionir bagi gerakan moderasi sosio-religius dan penyebarluasan wawasan kebangsaan demi komitmen kebangsaan melalui Idiologi Pancasila dan upaya mempertahankan keutuhan Negara Kesatuan Republik Indonesia.

\section{Ucapan Terima Kasih}

Terima kasih kami sampaikan terutama kepada Ketua Lembaga Penelitian dan Pengabdian kepada Masyarakat (LPPM) Universitas Lampung atas fasilitas pendanaan melalui skema pengabdian unggulan Tahun Anggaran 2021. Ucapan terima kasih juga kami sampaikan kepada Kepala Sekolah, para dewan guru, para pengurus OSIS, serta para pelajar SMA YP Unila yang telah terlibat dalam kegiatan pengabdian kepada masyarakat ini.

\section{Daftar Pustaka}

Abdullah, Anzar. 2016. Gerakan Radikalisme Dalam Islam: Perspektif Historis. Jurnal ADDIN Vol. 10. No. 1. Makassar: Ilmu Politik FISIP Universitas Pejuang Republik Indonesia (UPRI) Makassar. p. 1-25.

Aswar, Hasbi. 2015. Organisasi Nahdlatul Ulama Memerangi Radikalisme Politik Islam Di Indonesia. Tesis Program Studi Hubungan Internasional Universitas Islam Indonesia. Yogyakarta: Program Pascasarjana Fakultas Psikologi Dan Ilmu Sosial Budaya Universitas Islam Indonesia.

AS Hikam, Muhammad. 1996. Demokrasi dan Civil Society. Jakarta: Pustaka LP3ES.

Dahlan, Fahrurrozi. 2012. Fundamentalisme Agama: Antara Fenomena Dakwah dan Kekerasan Atas Nama Agama. Academic Journal for Homiletic Studies Vol. 6. No. 2. Mataram: Ilmu Dakwah IAIN Mataram. p. 331-346. 
Eva Pardiana. 2018. ’Tinggi, Potensi Radikalisme di Lampung", https://m.mediaindonesia.com/amp/amp detail/ 150531-tinggi-potensi-radikalisme-di-lampung (diakses pada 18 November 2019 Pukul 23.24 WIB).

Imansari, Galih Nitra. 2019. Peran Ulama Nahdlatul Ulama Dalam Menangkal Radikalisme Di Provinsi Jawa Timur. Tesis Program Studi Komunikasi Penyiaran Islam Universitas Islam Negeri Sunan Ampel. Surabaya: Program Pascasarjana Universitas Islam Negeri Sunan Ampel.

Mursalin Yasland. 2016. "Enam Daerah di Lampung Rawan Radikalisme", https://m.republika.co.id/amp/oh3gwg365 (diakses pada 13 Februari 2020 14.16 WIB).

Nafis, Muhammad Wahyuni. 1996. Rekonstruksi dan Renungan Religius Islam. Jakarta: Paramadina.

Ratnasari, Dwi.2010. Fundamentalisme Islam. Jurnal Dakwah dan Komunikasi Vol. 4. No. 1. Purwokerto: Jurusan Dakwah STAIN Purwokerto. p. 40-57.

Raymundus Rikang. 2019. "Radikalisme Pegawai Negeri”.https://majalah.tempo.co/amp/laporanutama/158644/radikalisme-pegawai-negeri (diakses pada 7 Maret 2020, pukul 16.00 WIB).

Robi, Ulzikri Ahmad. 2019. Politik Nahdlatul Ulama Dalam Pemilihan Presiden Dan Wakil Presiden 2019. Skripsi Jurusan ilmu Pemerintahan Universitas Lampung. Lampung: FISIP Universitas Lampung.

Rosidah, Nur. 2012. Fundamentalisme Agama. Jurnal Walisongo. Vol. 20. No. 1. Semarang: IAIN Walisongo Semarang. p. 1-24.

Rozi, Fahmil. 2018. Civil Society Dan Radikalisme: Studi Atas Dukungan Nahdlatul Ulama Terhadap Pembubaran Hizbut Tahrir Indonesia. Skripsi Program Studi ilmu Politik Universitas Islam Negeri Syarif Hidayatullah. Jakarta: FISIP Universitas Islam Negeri Syarif Hidayatullah.

Wibowo, Agus. 2012. Pendidikan Karakter: Strategi Membangun Karakter Bangsa Berperadaban. Yogyakarta: Pustaka Pelajar.

Zubaedi. 2011. Desain Pendidikan Karakter: Konsep dan Aplikasinya dalam Lembaga Pendidikan. Jakarta: Kencana. 